\title{
Article
}

\section{Introducing Johannesburg's new cycle lanes to potential student users: experiences, impact and recommendations}

De Wet, T., Dzinotyiweyi, T. and Ellison, George Available at http://clok.uclan.ac.uk/35531/

De Wet, T., Dzinotyiweyi, T. and Ellison, George ORCID: 0000-0001-8914-6812 (2020) Introducing Johannesburg's new cycle lanes to potential student users: experiences, impact and recommendations. Journal of American College Health . ISSN 0744-8481

It is advisable to refer to the publisher's version if you intend to cite from the work. http://dx.doi.org/10.1080/07448481.2020.1817031

For more information about UCLan's research in this area go to http://www.uclan.ac.uk/researchgroups/ and search for <name of research Group>.

For information about Research generally at UCLan please go to http://www.uclan.ac.uk/research/

All outputs in CLoK are protected by Intellectual Property Rights law, including Copyright law. Copyright, IPR and Moral Rights for the works on this site are retained by the individual authors and/or other copyright owners. Terms and conditions for use of this material are defined in the policies page.

\section{CLoK}

Central Lancashire online Knowledge www.clok.uclan.ac.uk

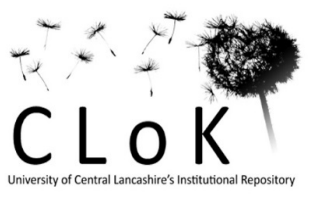


Introducing Johannesburg's new cycle lanes to potential student users: experiences, impact and recommendations

De Wet $\mathrm{T},{ }^{1}$ Dzinotyiweyi $\mathrm{T},{ }^{1}$ and Ellison $\mathrm{GTH},{ }^{1,2}$

${ }^{1}$ CAT, University of Johannesburg, Gauteng, South Africa

${ }^{2}$ Centre for Data Innovation, University of Central Lancashire, Preston, UK; gthellison@uclan.ac.uk

https://doi.org/10.1080/07448481.2020.1817031

\author{
Abstract \\ Objective: The present study evaluated an intervention designed to introduce University students as potential users \\ of Johannesburg's cycle lanes.
}

Participants: A total of 393 undergraduate and postgraduate students from the University of Johannesburg took part.

Methods: Following cycling and safety training, participants undertook a $1.2 \mathrm{~km}$ supervised cycle ride between University of Johannesburg campuses using loaned bicycles. The evaluation of the intervention drew on quantitative and qualitative data collected using participant questionnaires; and fieldworkers' photographic and reflective accounts.

Results: Perceived cycling competency improved following the intervention, though similar proportions of participants became more and less interested in bicycle ownership (7-8\%). The physical effort entailed; and flaws in the design and maintenance of cycle lanes (that affected utility and safety) were the strongest themes emerging from the qualitative analyses.

Conclusions: The supervised cycle rides improved perceived cycling competency, but also enabled participants to reappraise the potential benefits and desirability of bicycle ownership.

Key words: bicycle, cycling, South Africa, University, student

\title{
Introduction
}

Following the completion of the "university corridor" cycle lanes in 2015 as part of the City of Johannesburg's "Corridors of Freedom" non-motorised transport strategy, 1,2 the University of Johannesburg (UJ) was commissioned to undertake a series of projects with students, residents and commuters to: evaluate attitudes towards, and use of, the new cycle lanes; identify potential barriers to the uptake of cycling thereon; and promote the use of these lanes as an alternative to motorised transport. The first of these projects ${ }^{3}$ - which involved a survey of undergraduates to identify demographic and socioeconomic variation in cycling competency and bicycle ownership/access - suggested that interventions aiming to promote cycle-based transport amongst UJ students would need to address the substantial proportion who do not: know how to ride a bicycle; own/have access to a bicycle; or have recent experience of cycling as a form of transport. Such interventions would also need to address the far larger proportion of female students who lacked cycling competency. ${ }^{3}$ 
The present study sought to incorporate these findings into the design and implementation of cycle promotion events that would provide UJ students with both advice and training, and opportunities to experience cycling on the City's new cycle lanes using loaned bicycles and cycle rides supervised by experienced cyclists (both male and female). This article describes the first of these events and summarises the mixed-methods process and outcome evaluations that were conducted to assess both their potential feasibility and their impact on perceived cycling competence, and attitudes towards cycle ownership, amongst participants. A secondary aim of the evaluations was to collate the views and experiences of intervention staff and participants towards the cycle lanes, and cycling thereon; and to generate suggestions and recommendations for enhancing the safety and utility of these lanes from the perspective of potential future users.

\section{Methods}

\section{Intervention design}

The intervention was primarily designed to provide UJ students with an opportunity to safely experience cycling on Johannesburg's new cycle lanes, under the supervision and guidance of experienced cyclists. Given the findings of the previous survey of cycling competency and bicycle ownership/access amongst UJ undergraduates, ${ }^{3}$ the training and supervision offered to participants was specifically designed to match the needs of those with differing levels of competency and experience. This approach included competency- and safety-focused training for: those who did not know how to cycle; those who had not recently ridden a bicycle; and those with limited experience of cycling on roads and/or for transport (rather than for leisure/recreation). The intervention addressed the limited numbers of students who owned/had access to a bicycle by sourcing sufficient bicycles to ensure that all participants could be loaned a well-serviced bicycle, in safe working order, for the duration of the intervention. The intervention also recruited both male and female staff to facilitate 'gender-matched' training and supervision, and to demonstrate that cycling was accessible, acceptable and appropriate for both men and women. Finally, to demonstrate the potential utility of cycling as a form of transport and to provide first-hand experience of using the City's new cycle lanes, the intervention's supervised cycle rides were designed to make extensive use of the lanes connecting the University's Auckland Park Kingsway and Auckland Park Bunting Road campuses (known as APK and APB, respectively).

\section{Participant recruitment and intervention implementation}

Participants were recruited using hundreds of posters displayed throughout the APK and APB campuses, which provided a brief introduction to the "As'Vaye!" Project (meaning "Let's Go!" in Zulu), and indicated when and where participants could receive further information, training and advice, including the temporary loan of a bicycle. Over a two week period (from $26^{\text {th }}$ February to $7^{\text {th }}$ March 2016), project staff erected two branded gazebos on the extensive lawns opposite the Student Centre on the University's APK campus. The first had separate desks for registration and for conducting the 'before-' and 'after-' intervention interviews. At the second, four experienced cyclists (three male and one female) from the 'Bon4Kasi' cycling club in Soweto, who acted as instructors for the intervention, allocated 
one of the 30 loan bicycles available to registered participants. These bicycles comprised: 20 Dutch-style bicycles, with three gears and fore and aft brakes, that had been donated to the City of Johannesburg by the Cape Townbased NGO 'BEN' (www.benbikes.org.za); and 10 Qhubeka bicycles (www.qhubeka.org), with a single gear and backpedal brake, provided by the Buffalo Bike NGO (www.buffalobicycle.com/). The instructors also provided each participant with safety equipment (a helmet and reflective bandolier), and presented safety training briefs to groups of up to 25 participants at a time, before accompanying them on a supervised $2.4 \mathrm{~km}$ cycle ride from the APK campus to the APB campus (and back). For participants who did not know how to ride a bicycle, smaller groups of up to five participants at a time were given introductory lessons within the grounds of the APK campus by one of the instructors. The streaming of participants according to their cycling competency; and the organisation of group cycle rides - supervised by instructors, and accompanied by other members of the intervention team who were themselves experienced cyclists - emerged as best practice following a review of the first day of the intervention, during which the organisation and management of both the intervention itself and the evaluation were piloted. This review also identified: a number of weaknesses in data collection practice which posed substantial risks to the completeness of both pre- and post-intervention data; and concerns regarding the safety and security of participants and intervention resources (including the theft of a bicycle). These were addressed by subsequent improvements in participant registration, data management, bicycle allocation and training; and by ensuring that adequate supplies of drinking water were available for participants after they had completing their cycle ride (which helped to ensure participants were not dehydrated during the post-intervention evaluation interview).

\section{Process and outcome evaluation data}

The primary quantitative and qualitative data used to evaluate the intervention were generated from interviews conducted both before and after the intervention, using fieldworkers trained in the use of questionnaires uploaded to mobile phones. These questionnaires used open- and closed-ended items to collect: demographic, economic and social information about each participant; as well as self-reports of cycling competency, experience and behaviour; and attitudes towards, and experience of using, Johannesburg's new cycle lanes (see Table 1). Five items (relating to: the types of cycle journeys undertaken; cycle lane use; cycle helmet use; perceived cycling competence; and attitudes towards cycle ownership) were repeated in questionnaires completed before and after the intervention to assess the impact of the intervention on each of these criteria. To provide additional qualitative data on both the context and process of the intervention, fieldworkers were requested to take photographs and video footage whenever time permitted, and to write brief reflections at the end of the two weeks to gauge their impressions of participants' engagement with, and experiences of, the intervention.

\section{Analysis}

Descriptive quantitative analyses of data from closed-ended items in the 'before-' and 'after-' intervention questionnaires, were used to summarise the frequency (and percentages) of responses to items in each questionnaire. The strength and direction of any changes in each of the five items repeated in both of these questionnaires was then assessed by calculating the odds ratios and $95 \%$ confidence intervals (OR; $95 \% \mathrm{Cl}$ ) of any differences in the distribution of responses 'after' vs. 'before' the intervention; the null hypothesis being that the 
intervention would result in no change. All free-text open-ended items within the 'after'- intervention questionnaire were subjected to thematic analysis. ${ }^{4}$ Thematic analysis was also applied to photographs and video footage captured on fieldworkers' mobile phones, and to the brief written reflections submitted by fieldworkers at the end of the intervention.

\section{Ethics and indemnity}

Ethical approval was received from the Faculty of Humanities at the University of Johannesburg. Students were asked to participate in the evaluation after they registered to participate in the cycle ride. If they agreed, they were asked to sign an informed consent form stating that their completion of each of the evaluation questionnaires was voluntarily and would remain anonymous. Student safety was a key concern to the research team. In this context, students were given a detailed safety talk explaining the risks of cycling outside campus and the potential injuries that could happen as a result of unsafe cycling. Students were given time to read through the indemnity form before signing this, and all were required to wear a safety helmet and reflective bandolier while cycling on- or off-campus.

\section{Results}

\section{Recruitment}

Rainy weather on two of the nine weekdays allocated to the intervention meant that this, and the collection of data for its evaluation, only took place on seven of the nine weekdays anticipated. Nonetheless, a total of $n=393$ participants consented to participate in the study and completed the study registration process. Numerous other students visited the intervention's gazebos to learn more about the As'Vaye! Project and the new cycle lanes the intervention sought to promote. Additional interest was generated by visits made to the Kingsway campus by members of the 'SuperCycling Club' (SCC; a "community of like-minded cycling enthusiasts" www.cyclelabclub.co.za) and a team from the City of Johannesburg Transport Department (CJTD; www.joburg.org.za/transport). The SCC and CJTD brought with them: eight top of the range racing bicycles; and five electric pedal bikes/scooters, respectively each of which UJ students could try out within the campus grounds. Together these initiatives helped to sustain a steady stream of curious and interested students from which volunteers to participate in the As'Vaye! Project were recruited.

Of the $n=393$ participants who registered to participate, $n=371$ completed the 'before-' intervention questionnaire, and $n=303$ completed the 'after-' intervention questionnaire. Using unique anonymised ID numbers, allocated to each participant at registration, it was possible to determine that $n=281$ participants successfully completed both questionnaires, whilst $n=90$ and $n=22$ only completed the 'before-' or 'after-' intervention questionnaires, respectively. While this means there were a modest number of participants with missing baseline data $(n=22 / 393$; $5.6 \%$ ), loss to follow-up was substantial ( $n=90 / 393 ; 22.9 \%)$. Key demographic, economic, social and cycling-related characteristics of participants completing the 'before-' and 'after-' questionnaires, and both, have been summarised in Table 2. This permits an assessment of potential bias associated with missing pre-intervention data and loss to follow-up. From Table 2 it is clear that, for the most part, there was little evidence of any substantial differences 
between participants responding to only the 'before-', only the 'after-' or both questionnaires. However, there were apparent differences in bicycle ownership, cycling for exercise, and the use of cycle helmets and cycle lanes - which suggest that participants lost to follow-up were more likely to be more experienced 'sports' cyclists, whose views of the intervention (and particularly of cycling on the cycle paths) are likely to have been rather different to those who completed both questionnaires. For this reason, the analyses that follow need to be interpreted with this potential bias in mind.

This issue aside, Table 2 indicates that participants tended to be young (around three-quarters of whom were $\leq 22 y r s$ old) and male (only around $25 \%$ being female) undergraduates, most of whom self-identified as 'African'- a sample that contrasts somewhat with the gender and population group distribution of UJ students (just over half of whom are female, and around $20 \%$ of whom self-identify as 'Coloured', 'Indian' or 'White'). Indeed, in the survey undertaken prior to designing the intervention, ${ }^{3}$ around two thirds were female, and it therefore appears that gender strongly influenced participation in the cycle promotion intervention. Nonetheless, in line with this survey, ${ }^{3}$ few of the intervention participants owned a car and, while most lived off campus, travelling predominantly involved walking from nearby accommodation or using public transport. Relatively few of those who completed the 'after-' intervention questionnaire reported owning a bicycle (just 6\%), a figure comparable to the low rates of bicycle ownership amongst Gauteng households surveyed by the Gauteng City Regional Observatory ${ }^{5,6}$ yet substantially lower than that observed amongst the $n=90$ participants lost to follow-up (i.e. those completing only the 'before-' intervention questionnaire), $32.9 \%$ of whom reported that they owned a bicycle). Bicycle ownership amongst intervention participants was also lower than that reported by the UJ students previously surveyed (26\%), ${ }^{3}$ as was cycle-based transport - only one of the intervention participants selecting cycling as their only 'normal mode of transport' (see Table 2), while $n=77 / 427$ (18\%) of those previously surveyed ${ }^{3}$ reported that they had 'last cycled' for transport. Although differences in the items used to determine cycle-based transport may have contributed to the differences observed between these two studies, the differences in bicycle ownership do suggest that cycle-owning students (and those who used bicycles for transport) were less likely to participate in the cycle promotion intervention; and that those who did were more likely to have disengaged with the final phase of the evaluation (i.e. to have been lost to follow-up). However, closer examination of the $n=281$ participants completing both the 'before'and 'after-' intervention questionnaires revealed that $n=80$ (29.3\%) reported owning a bicycle in the first of these questionnaires, while only $n=17(6.2 \%)$ did so in the second. It is therefore possible that the answers to this question in the 'before-' questionnaire were also susceptible to response and/or prestige bias ${ }^{7}$ which would, for example, have been the case had participants believed that they would not be able to register and/or loan a promotional bicycle had they reported not owning their own bicycle at the outset.

Despite the fact that only one participant selected cycling as their only 'normal mode of transport', levels of selfreported cycling competency were high (around 50\% considering themselves 'expert' cyclists), as was interest in owning a bicycle (at around 80\%). Nevertheless, most participants reported cycling primarily for recreation and/or exercise, with relatively few travelling to the shops or commuting to/from campus by bicycle. Indeed, very few reported having used Johannesburg's new cycle lanes prior to the intervention. Taken together, these characteristics 
suggest that the study recruited volunteers who were motivated to participate because they were relatively inexperienced cyclists and aspiring (as opposed to existing) bicycle owners.

A comparison of quantitative data collected from participants completing both 'before-' and 'after-' questionnaires Focusing on those $n=281$ participants who completed both the 'before-' and 'after-' questionnaires, Table 2 also provides an early indication of the likely impact of the intervention on each of the five items that were repeated in these two questionnaires. Formal statistical analysis of changes in responses to these five items are provided in Table 3, which indicate that there were striking changes in four of these: the types of cycle journeys taken (with increases in the number of journeys 'to/from campus' and for 'recreation'); the use of cycle helmets (which increased from $29 \%$ to almost $100 \%$ ); the use of Johannesburg's cycle lanes (which increased from just $17 \%$ to over 90\%); and the proportion of respondents who considered themselves 'expert' rather than 'beginner/intermediate' cyclists (which increased from $41 \%$ to $52 \%$ ). To a large extent, the changes in responses to the first three of these items are simply likely to reflect the content of the intervention itself (in which participants were given access to bicycles, safety equipment and advice, and were able to join small groups of cyclists accompanied by experienced instructors on supervised cycle rides that made good use of the cycle paths, with the campus as the start and end point). As such, the changes in these three items may simply confirm that the intervention took place as planned, and that participants were exposed to each of the key aspects as intended (particularly the opportunity to use appropriate safety equipment and to familiarise themselves with Johannesburg's new cycle lanes).

Of greater importance, in terms of evaluating the possible impact of the intervention on the confidence and aspirations of participants, was the substantial improvement in self-reported cycling competency and the absence of any clear change in the proportion of participants who were interested in owning a bicycle (see Table 3). These findings suggest that the intervention improved the confidence/perceived cycling competency of participants, but did not change the level of interest in bicycle ownership overall. However, closer examination of responses from the n=273 participants who provided an answer to the 'interested in owning a bicycle' item in both the 'before-' and 'after-' questionnaire, revealed that there were $n=19$ participants who became 'interested' in owning a bicycle following the intervention and $n=23$ who became 'uninterested'. Thus, while the intervention did not alter aspirations for bicycle ownership amongst the vast majority of participants ( $n=231 ; 85 \%)$, there was a small number of participants whose aspirations changed following the intervention ( $n=19$ becoming 'interested', and $n=23$ becoming 'uninterested'; a change of $7 \%$ and $8 \%$, respectively).

\section{Qualitative data collected from participants completing both before and after questionnaires}

To better understand how, and why, the intervention resulted in a significant improvement in perceived cycling competency yet failed to further strengthen interest in bicycle ownership overall, thematic analyses were conducted on the free text comments for each of the six open-ended items included in the 'after-' questionnaire. These themes have been summarised in Table 4, and emerged from 'experiences', 'challenges', 'suggestions' and 'comments' of participants regarding: the supervised cycle rides; the cycle lanes on which these took place; and the bicycles that each of the participants had been loaned. As such, there was extensive overlap and continuity within material 
emanating from the six different open-ended items in the 'after-' intervention questionnaire, across which three broad 'types' of participant experiences emerged: there were those who were enthused and exhilarated by the supervised cycle ride, and appeared willing to overcome $(\mathrm{m}$ )any of the challenges and difficulties they encountered; while others appeared more sceptical, their enjoyment of the cycle ride tempered by reservations about safety, practicability and the effort involved; and finally there were those who were disillusioned or discouraged by their experiences of riding on the cycle lanes, not least when this had (further) weakened their confidence as cyclists and road users.

Each of these three groups had much to say about the cycle lanes, the bicycles they had been loaned, their experience of riding these, and of doing so as part of a group of cyclists. Structural shortcomings in the design, condition and scope of the cycle lanes featured in all of their accounts, which generally found the lanes to be: too narrow (particularly for use by more than one cyclist at a time); too close to, and inadequately separated from, busy roads and other road users; poorly integrated with, and sign-posted at, road intersections; and poorly finished, maintained and policed (particularly with respect to puncture hazards and obstacles, including parked vehicles).

Participants also found the rationale for where the cycle lanes started and ended perplexing and confusing, and were keen to see the lanes enhanced and extended to improve not only their ease of use and comprehensiveness, but also to establish these as recognised and accepted components of Johannesburg's transport infrastructure. These perceived limitations led a good number of participants to express concern about the potential dangers and difficulties of using the cycle lanes. Such concerns appeared highest amongst those who lacked experience and/or confidence when cycling, and were exacerbated by a lack of familiarity with the particular bicycle model/design they had been loaned to use. Indeed, even participants who considered themselves experienced and competent cyclists could find the bicycle they had been loaned challenging or awkward to use.

Yet by far the most dominant theme emerging from participants' experiences of the supervised cycle ride itself concerned the physical effort required, and how tough they found it to cycle the modest distance (just $1.2 \mathrm{~km}$ each way) between the University's APK and APB campuses. Many participants reported that it was hard work to climb the modest slope involved - a section of which the fieldworkers dubbed the "invincible hill" (a play on the word "invisible") because the route appeared ostensibly level. Indeed, using the online tool CalcMaps (https://www.calcmaps.com/map-elevation/) it was possible to confirm that the gradient of the 'invincible hill' section of the cycle ride was negligible $(\approx 0 \%)$, while the gradient from start to finish fell well below $1 \%$. However, to some extent the effort involved is likely to have been accentuated by travelling in groups, given that these cycled slowly and stopped frequently so that any momentum achieved was repeatedly lost (which may have also been frustrating for more experienced and accomplished cyclists). Indeed, since the intervention's supervised cycle rides included participants of mixed ability using a range of different types/designs of bicycles, these rides were likely to be contexts in which the difficulties and challenges experienced by some participants could have detracted from the enjoyment of others. Certainly, while relatively few participants described struggling to stay on their bicycle and (safely) within the cycle lane, and few reported feeling uncomfortably vulnerable to motor vehicles (whether on 
those sections of the cycle lanes adjacent to roads, or when crossing busy intersections), their experiences do appear to have alarmed and discouraged some of the other participants who might otherwise have grown in confidence by successfully avoiding or overcoming these challenges on their own.

Nonetheless, for the most part, these structural and experiential factors (not least those 'experienced' second-hand) do not appear to have detracted from the sense of achievement most participants described. Many clearly enjoyed the supervised cycle ride, and felt exhilarated when they had completed this (not least given the effort many felt this entailed). The confidence this inspired is likely to have contributed in no small part to the improvement in perceived cycling competence reported in the 'after-' intervention questionnaire. Moreover, given that the vast majority of participants (>85\%) expressed an interest in bicycle ownership before the intervention, there was little scope for improvement as a result of the intervention. It is therefore perhaps reassuring that only a small number of participants went off the idea of owning a bicycle (perhaps because they found the intervention stressful, difficult or frightening) and that a similar number became interested in owning a bicycle following the intervention (presumably because they found this exhilarating, encouraging and persuasive).

\section{Photographs and video footage captured by fieldworkers}

Photographs and video footage captured on fieldworkers' phones provided rich contextual data on each component of the intervention: from the arrangement of the registration, survey and bicycle allocation gazebos on the extensive lawns within the grounds of the APK campus; to the safety presentations and warm-up exercises led by members of the Bon4Kasi cycling club; and the passage of the cycle rides from the APK campus to the APB campus and back (see Figure 1). The photographs reveal the level of engagement, enthusiasm and excitement of participants preparing for their cycle rides, arranged in a wide circle to perform their pre-trip warm-up and stretching exercises; or gathered around instructors demonstrating how each of the two types of bicycles worked (and, in particular, the workings of the back pedal break on the Qbeka bicycles). Photographs and footage of the trips themselves reveal the level of exertion required from many of the participants as they got underway; the unsteadiness of others as they became familiar with using the bicycles; and the care taken by instructors cycling up and down the road alongside the cycle lane offering encouragement and advice to participants within the lanes. On sections of the route where there was heavier traffic moving along the road beside the cycle lane, and where the cycle lanes ended at junctions, roundabouts and traffic lights, photographs indicate the close proximity of cars, buses and lorries, and the care required to avoid collisions with vehicles turning left across the path of the cyclists. In a number of places along the route, fieldworkers captured images of a range of potential hazards, challenges and barriers, including: cars illegally parked across the cycle lane (which required participants, aided by instructors keeping a careful eye on the traffic, to move into the road to pass the parked vehicles before rejoining the cycle lane); broken glass, rubbish, tree branches and other plant debris strewn across cycle paths posing a slip hazard or puncture risk; and incomplete and poorly maintained sections of the cycle paths (including large concrete inspection covers that were poorly fitted, broken or missing, and might cause a bicycle to slip, jolt, stall or get damaged). Finally, photographs taken of participants arriving at the APB campus (the mid-point of the cycle ride) and again on their arrival back at the APK campus, reveal how tired some felt, one of whom was photographed walking the last $50 \mathrm{~m}$ or so while others were taking a breather 
as they prepared to journey back to the APK campus or congratulated themselves on the achievement of arriving back there.

\section{Reflections of intervention fieldworkers}

The brief written reflections requested from fieldworkers at the end of the intervention revealed a number of confirmatory, contradictory and novel insights into the experiences of participants which, together with the photographs and video footage they had generated (Figure 1), offered an opportunity to triangulate these with the quantitative and qualitative data provided by participants. Fieldworkers confirmed that there had been considerable interest, enthusiasm and excitement amongst participants. Since relatively few participants owned a bicycle (which inevitably limited their ability to travel by bicycle), many were eager to try out one of the promotional bicycles on loan and to contribute their ideas (such as the possibility of providing bicycles on each of the University's campuses for students to use both within and between these). Nonetheless, fieldworkers also revealed that some participants felt that cycling on the cycle lanes, and cycling per se, was simply not "cool"; and similar views on cycle helmets (that these were "ugly", ill-fitting, and would ruin elaborate hair styles) may have discouraged some students from participating.

Drawing on both their impressions of participants and their own experiences of cycling on the cycle lanes (and of assisting the instructors supervising the cycle rides), fieldworkers agreed that intersections, roundabouts and traffic lights were (experienced as) very difficult to negotiate (safely), and that the design of such intersections paid little attention to the needs of cyclists/cycle lane users. More generally though, participants' experiences of the supervised cycle rides, and of the cycle lanes on which these took place, were felt to be dominated by: the level of exertion and care required to cycle safely on lanes that were felt to be narrow, steep and poorly maintained; and dealing with pedestrians and "interference from taxis" (and other vehicles using or parking across the lanes). Fieldworkers' reflections drew particular attention to how tired and thirsty participants were when they returned from their supervised cycle rides (and that adequate supplies of water were not always available, and would have been sensible to provide for all participants - perhaps before as well as after their cycle rides).

Being tired and/or thirsty was also felt to have influenced participants' views on, and engagement in, the evaluation interviews (particularly the post-intervention interviews conducted using the 'after-' questionnaire). Fieldworkers reflected that (some) participants felt these were "unnecessary", overly long, "repetitive" and "tiring/annoying" observations that might have contributed to the substantial loss to follow-up (i.e. $n=90 / 393,22.9 \%$ of participants not completing the 'after-' questionnaire; see above). Fieldworkers also felt that this may have led participants to provide less detailed and/or more critical responses to the closed- and open-ended items in the 'after-' intervention questionnaire.

\section{Discussion}

It is clear from the present study that cycle promotion events can attract substantial interest from higher education students in South Africa, including those with varied cycling competency. While more experienced and cycle-owning 
students appeared less likely to participate in (and/or complete the evaluation of) the intervention, female students were also disproportionately less likely to participate than males. Nonetheless, exposure to cycling training, advice and equipment enhanced participants' perceptions of their cycling competency, and although a small number of participants (15\%) changed their minds regarding bicycle ownership following a supervised cycle ride on Johannesburg's new cycle lanes, a very similar number became interested and lost interest in owning a bicycle as a result ( $7 \%$ and $8 \%$, respectively). Given the nature of participant recruitment (i.e. by invitation rather than by obligation or reward), it may not be surprising that $85 \%$ of participants were interested in owning a bicycle even before the intervention took place. As such, the scope for improvement was limited, and the absence of an overall increase in bicycle ownership aspiration after the intervention may not be surprising. However, notwithstanding measurement error, the fact that some participants changed their minds (in both directions) suggests that interest in bicycle ownership was sensitive to the intervention. Moreover, it could be argued that dissuading participants from owning a bicycle (particularly those with insufficient competence and/or confidence) might be construed as a beneficial impact of the intervention; and from this perspective the intervention would appear doubly successful. Indeed, these findings (and particularly the improvement in perceived competence following the training and cycle ride provided by the intervention) suggest that such interventions are likely to be successful in promoting cycling amongst similar participants in similar contexts. Whether this interest translates into an increase in the uptake of cycling (in this instance, amongst students using bicycles when commuting to, from, and between, campuses) will nonetheless depend upon the accessibility of bicycles, whether owned or loaned - an issue evident from the large number of participants who did not own a bicycle.

While the intervention described in the present study can broadly be described as a success, the collection of quantitative and qualitative data during the implementation of the intervention (and the evidence these data provide) nevertheless identify a number of potential limitations that warrant further attention. Of particular importance is the likelihood that the recruitment of participants was highly selective, and that the students who volunteered to participate were disproportionately male, and those who: were already interested in the possibility of commuting to/from university by bicycle; had favourable attitudes towards cycling (and, perhaps, towards Johannesburg's new cycle lanes); but did not own a bicycle and were therefore attracted by the opportunity to loan a bicycle provided by the As'Vaye! Project. While this may not pose a serious concern to the City of Johannesburg's efforts to see its new cycle lanes put to use (by anyone willing and able to do so, at this early stage of their implementation), it does mean that the type of promotional event examined in the present study may not be effective at attracting potential users who are female, or who are more indifferent, sceptical or unconvinced about the potential utility, and benefits, of cycling and of Johannesburg's new cycle lanes. For this reason, it will be necessary to assess the impact of such interventions on less selective groups of participants (perhaps by exposing all university students to such interventions when they first arrive, or by recruiting the support of university staff and student representative bodies to promote cycling), albeit with appropriate attention to the attendant ethical implications involved. 
Of lesser concern, though potentially important to the implementation and evaluation of future cycle promotion events, the theft of a bicycle during the piloting of the intervention examined in the present study, and the failure to collect baseline and follow-up data from a substantial number of participants ( $11.4 \%$ and $27.6 \%$, respectively) underlines the importance of robust management systems for such interventions. In the present study tighter control over the allocation and use of loaned bicycles, and the provision of training and supervision to participants streamed according to cycling competency helped to ensure that no further thefts occurred, and that participants were able to gain experience of using bicycles safely, in contexts appropriate to their ability. Given the risks of injury associated with cycling, not least to participants with limited expertise and limited experience of cycling on paths close to (and intersecting with) busy roads, the level of care applied in the present study's intervention proved to be necessary to ensure that no serious accidents occurred. However, it seems likely that the level of supervision required (and the necessity of working with groups of students) may have attenuated the potential impact of the intervention - not least on participants who might have benefitted from more freedom to experience cycling independently on the cycle lanes, and those who required more one-to-one support and advice. This is an inevitable consequence of the limited resources available to any such intervention, but is an important consideration for future promotional events were these to be over-subscribed. Indeed, subsequent events at the University of Johannesburg have generated growing interest amongst students, and have required careful management of supervisory and material resources, and of the expectations (and patience) of participants, many of whom have often had to queue for up to an hour before space became available on the next cycle ride (see Figure 1). Even in the present study, fieldworkers observed that participants completing the 'after-' intervention questionnaire were often tired and thirsty following the exertions of their supervised cycle ride, and they felt that this was likely to have affected the responses participants gave to this questionnaire. While this is likely to have undermined the precision of the impact assessment (wherever participants gave brief or uninformative responses in order to complete the questionnaire promptly, rather than delaying their departure by explaining any reservations they had), it is also likely to have reduced the level of detail provided and thereby the insights available on their experiences of the intervention.

Post-intervention data collection can be a challenge to any impact evaluation using a before-and-after design, and can run the risk of substantial loss to follow-up (as it did in the present study). However, by introducing the provision of water to participants after they had completed their cycle ride, and by reducing the number of items in the 'after-' intervention questionnaire (see Table 1), the present study addressed the risk of loss to follow-up and ensured that more participants were able to explain, in some detail, their experiences (both good and bad) of the intervention. To some extent these decisions appear to have had their desired effect (see Table 4), although loss to follow-up remained high (22.9\%; see Table 2).

These issues aside, the present study generated substantial insights into the practicability of cycling for students commuting to, and between, the University's APK and APB campuses. Notwithstanding the small proportion of participants who owned bicycles, the two principal issues that emerged from the experiences of fieldworkers and participants related to: the physical effort required to cycle (even the short distance between campuses); and design- and maintenance-related concerns about the cycle lanes that made these difficult to use and potentially 
unsafe. To some extent the importance afforded 'physical effort' in the accounts of fieldworkers and participants may have been accentuated by their unfamiliarity with the promotional bicycles they were loaned to use, and by the slow and faltering pace of participants as they cycled between campuses in supervised mixed-ability groups. Certainly, a number of participants cited those ahead of them braking frequently and cycling slowly as one of the 'challenges' they had experienced on their supervised cycle ride (see Table 4). However, it may not be surprising that, despite their age, these students found the cycle trips strenuous given that: so few owned/had access to bicycles; so many routinely used public or private transport; and most had primarily cycled for recreation or exercise, and only sometime in the past (see Table 3).

Attaining a sufficient level of physical fitness to cycle even comparatively short distances can pose a challenge to those with predominantly sedentary lifestyles, ${ }^{8,9}$ and this is acknowledged as a substantial potential barrier to the uptake of cycling. ${ }^{9-11}$ Nonetheless, studies of commuters who have recently taken up cycling attest to the rapidity with which their fitness improves, and the associated benefits they experience as a result. ${ }^{10} \mathrm{It}$ is therefore reassuring, in the present study, that despite the large number of participants who felt that the cycle ride had been physically challenging and exhausting, the exhilaration at having persevered and completed the ride meant that substantial numbers felt their cycling competency had improved (albeit, perhaps, their confidence in their competency); while very few changed their minds about their interest in owning a bicycle.

There nevertheless remain a number of issues identified by fieldworkers and participants regarding the design and maintenance of the cycle lanes on which the intervention's cycle rides took place - issues that reflect, in many instances, deep-seated concerns about the safety of cycling thereon. Foremost amongst these were the perceived risks from motor vehicles, both at intersections (where an apparent lack of consideration for cyclists meant that traffic lights and signs did not indicate where and how they should be navigated by cyclists), and on sections of the cycle lanes that were situated adjacent to or within busy roads (some separated with raised yellow studs, some simply demarcated with painted lines). Vehicles driving into and parking on cycle lanes were commonly cited as serious obstructions, often requiring cyclists to mount the pavement or move into the road to circumvent them manoeuvres that brought the cyclists into conflict with pedestrians or posed a risk of collision with motor vehicles (see Figure 1 for examples thereof). Some participants also found the absence of a substantive physical barrier between cycle lane and road very disconcerting after they found that their bicycle could cross these with ease and enter the road. More commonly, participants cited the presence of broken bottles, garbage, leaves and branches in the cycle lanes as potential obstacles and puncture hazards, and Figure 1 also includes photographs of structural flaws (a broken concrete inspection cover, and an unsurfaced section of path) likely to pose similar risks to cyclists.

For these reasons, most participants felt that the cycle lanes were (or, at least, appeared to be) poorly maintained; and a common suggestion was to ensure these were better monitored and policed (particularly with respect to illegally parked vehicles blocking the lane). While these observations - from participants who were (for the most part) first time users of Johannesburg's new cycle lanes - offer tangible suggestions for enhancing the utility and safety of these lanes; the problems and concerns involved do not appear to have dissuaded (more than a small 
number of) participants from an interest in owning a bicycle (and, presumably, from aspiring to use these on the cycle lanes). Given that many cyclists elsewhere describe facing similar challenges, regardless of the quality and upkeep of the routes they use, ${ }^{11-14}$ it may be that those participants who take up cycling on Johannesburg's new cycle lanes will learn to cope with these challenges, and will not experience these as more than minor irritations as they grow in experience and confidence. Nonetheless, this does not mean that the fresh insights offered by novice cycle lane users are not important considerations for those designing and managing transport infrastructure; rather, these seem identify unnecessary barriers (and risks) to potential users that are worth addressing in order to optimise their contribution to the transport system.

These findings compliment research into the feasibility and desirability of promoting cycling amongst college and university students (and staff) in the United States ${ }^{15-17}$ and elsewhere. ${ }^{3,9,18}$ Together, these studies point to a number of important steps that further and higher education institutions can take to integrate cycling to, within and between their campuses; and to support the uptake of cycling by students (including those who lack the experience, means or confidence to take up cycling for transport). Given the wider health and environmental benefits of nonmotorised transport, and the potential cost savings involved, further research is warranted to evaluate the challenges and benefits experienced by institutions taking each of these steps towards cycling-enabled campuses, students and staff.

\section{Acknowledgements}

The intervention and evaluation described here forms part of a larger project funded by the City of Johannesburg to generate greater understanding of barriers to the uptake of the City's new cycle lanes. The intervention would not have been possible without the support of the Bon4Kasi cycling club and the four experienced club members (Sipho Tati, Raymond Rampolokeng, Marcia Majavu and Gift Mtjike) who acted as instructors and supervised the cycle rides that were central to the intervention; and we are very grateful for their generous and enthusiastic contribution. Interest in the intervention was also greatly enhanced by the visits made to the Kingsway campus by the 'SuperCycling Club' and the City of Johannesburg Transport Department, who provided opportunities for students to try out top-of-the-range racing bicycles and electric pedal bikes/scooters; and we are also very grateful for their support and encouragement. Finally we express our thanks to the fieldworkers involved in implementing the intervention and collecting data for the evaluation; thank you to: Tumelo Lavisa, Nsovo Mathebula, Thato Kgoele, Jabulani Ntombela, Masego Tabane, Rose Manapo, Louise Onalenna and Vimbai Mawela. George Ellison's participation in the Project was supported by the Worldwide Universities Network and the University of Leeds.

\section{References}

1. Harrison P, Rubin M, Appelbaum A, Dittgen R. Corridors of Freedom: Analyzing Johannesburg's ambitious inclusionary transit-oriented development. J Plan Ed Res. 2019;8:456-68. doi: 10.1177/0739456X19870312 
2. Johannesburg Development Agency. 2014/15 Integrated Annual Report; 2015. Available at:

https://www.jda.org.za/wp-content/uploads/20151120 JDA-Integrated-Annual-Report-2015 vFinal 17 DC-1.pdf. Accessed November 19, 2019.

3. De Wet T, Dzinotyiweyi T, Ellison GTH. How might bicycle ownership/access and cycling expertise influence the design of cycling promotion interventions at the University of Johannesburg? J Amer Coll Health 2020; 68:1-9.

4. Braun V, Clarke V. Using thematic analysis in psychology. Qual Res Psych. 2006;3:77-101. doi: 10.1191/1478088706qp063oa

5. Ellison GTH, De Wet T. In press. Structural and attitudinal barriers to bicycle ownership and cycle-based transport in Gauteng, South Africa. Arxiv 2019; submit/2935778.

6. Gauteng City-Region Observatory. Quality of Life Survey; 2013. Available at:

http://gcro1.wits.ac.za/qolviewer/Default.aspx?Type=2013S. Accessed November 19, 2019.

7. Daniel J. Sampling Essentials: Practical Guidelines for Making Sampling Choices, Sage, London, UK; 2012. doi: $10.4135 / 9781452272047$

8. Buckworth J, Nigg C. Physical activity, exercise, and sedentary behavior in college student. J Amer Coll Health. 2004;53:28-34. doi: 10.3200/JACH.53.1.28-34.

9. Shannon T, Giles-Corti B, Pikora T, Bulsara M, Shilton T, Bull F. Active commuting in a university setting: Assessing commuting habits and potential for modal change. Trans Pol. 2006;13:240-254. doi: 10.1016/j.tranpol.2005.11.002.

10. De Geus B, Joncheere J, Meeusen R. Commuter cycling: effect on physical performance in untrained men and women in Flanders: minimum dose to improve indexes of fitness. Scand J Med Sci Sports. 2009;19:179-187. doi: 10.1111/j.1600-0838.2008.00776.x.

11. Gatersleben B, Appleton KM. Contemplating cycling to work: attitudes and perceptions in different stages of change. Trans Res Part A. 2007;41:302-312. doi: 10.1016/j.tra.2006.09.002.

12. Fishman E, Washington S, Haworth N. Understanding the fear of bicycle riding in Australia. J Aus Coll Road Safety. 2012;23:19-27. doi: 10.1080/01441647.2015.1114271.

13. Fraser SDS, Lock K. Cycling for transport and public health: a systematic review of the effect of the environment on cycling. Eur J Publ Health. 2011;6:738-743. doi: 10.1111/obr.12379. 
14. Owens P. The Effect of Cycle Lanes on Cyclists' Road Space: Warrington Cycle Campaign; 2005. Available at: http://warringtoncyclecampaign.co.uk/. Accessed November 19, 2019.

15. Wuerzer T, Mason SG. Cycling willingness: Investigating distance as a dependent variable in cycling behavior among college students. Appl Geog. 2015;60:95-106.

16. Balsas CJ. Sustainable transportation planning on college campuses. Trans Pol. 2003;10:35-49.

17. Ransdell LB, Mason SG, Wuerzer T, Leung KM. Predictors of cycling in college students. J Amer Coll Health. 2013 Jul 1;61(5):274-84.

18. Bonham J, Koth B. Universities and the cycling culture. Trans Res D. 2010;15:94-102. 
Table 1. Open- and closed-ended items contained in the 'before-' and 'after-' intervention questionnaires used in the present study.

Questionnaire items (response categories)

Questionnaire

'before-'

'after-'

Demographic, economic and social characteristics

Gender (male/female)

$\square$

政

Population Group classification ('African', 'Coloured', 'Indian', 'White')

$\square$

冈

Year of birth (converted to age in 2016)

$\square \quad \mathbf{x}$

Level of study (undergraduate/postgraduate)

$\square$

$\mathbf{x}$

Source of study funding (bursary, study loan, family/self) ${ }^{1}$

$\square$

\section{$凶$}

Car ownership (yes, no)

$\square$

凶

Place of residence (on campus, off-campus neighbourhood) ${ }^{2}$

$\mathbf{x}$

$\square$

$\mathbf{x}$

Normal mode of transport (walking, cycling, bus/taxi, car)

$\square$

$\mathbf{x}$

Self-reported cycling competency, experience and behaviour

Cycling competency (don't know how, beginner, intermediate, expert)

$\square$

$\square$

Cycle ownership (yes/no-interested, no-interested) ${ }^{3}$

$\square$

$\square$

Interested in bicycle share/rental scheme (yes, no) ${ }^{3}$

冈

$\nabla$

Pro's of cycle ownership (avoid traffic, eco-friendly, speed, exercise, cheap) ${ }^{1}$

国

Con's of cycle ownership (cost, confidence, safety, time, theft, steep roads) ${ }^{1}$

$\square$

冈

When last rode a bicycle (month and/or year)

$\square$

冈

How frequently rode a bicycle (days per week)

Types of cycle journeys (campus, shops, work, exercise, recreation) ${ }^{1}$

唯

$\square$

$\nabla$

Use of cycle helmet (yes, no) ${ }^{3}$

$\square$

$\square$

$\square$

$\square$

Type of promotional bicycle used (single gear, fixed gear)

凶

$\sqrt{\square}$

Attitudes towards and experience of Johannesburg's cycle lanes

Awareness of Johannesburg cycle lanes (yes, no)

田

Use of Johannesburg cycle lanes (yes, no $)^{3}$

西

Likes and dislikes of Johannesburg cycle lanes (open-ended)

$\square$

Suggestions on improving Johannesburg cycle lanes (open-ended)

凶

$\square$

Experience of using the promotional bicycle (open-ended)

冈

$\square$

Challenges experienced while using the promotional bicycle (open-ended)

凶

$\square$

Further comments regarding Johannesburg cycle lanes (open-ended)

政

$\square$

$\square$

${ }^{1}$ Items that also included 'Other' as an open-ended option

${ }^{2} \mathrm{An}$ item that asked for additional information as an open-ended option

${ }^{3}$ Items that subsequently asked 'Why not?' as an open-ended option 
Table 2. Comparison of participants who completed only the 'before-', only the 'after-' or both the 'before-' and 'after-' intervention questionnaires.

\section{Questionnaire items}

Intervention questionnaire(s) completed

'before-' only 'after-' only 'before-' and 'after-' $\mathrm{n}=90 \quad \mathrm{n}=22 \quad \mathrm{n}=281$

$n(\%) \quad n(\%) \quad n(\%)$ $\mathrm{n}(\%)$

Demographic, economic and social characteristics

Gender

\section{Male}

Female

Age

$$
\begin{aligned}
& \text { 17-21yrs } \\
& 22 y r s \\
& 23-27 y r s
\end{aligned}
$$

Population Group
'African'
'Coloured'
'White'
'Indian'

Level of study

$$
\text { Undergraduate }
$$

Postgraduate

Source of study funding

Bursary

Study loan

Family/self

Car ownership

$$
\text { Car }
$$

No car

Place of residence

On campus

Off campus

Normal mode of transport

$$
\begin{aligned}
& \text { Walking } \\
& \text { Cycling } \\
& \text { Bus/taxi } \\
& \text { Car }
\end{aligned}
$$

Self-reported cycling competency, experience and behaviour

$65(72 \%)$
$25(28 \%)$

$36(40 \%)$

$31(34 \%)$

$23(26 \%)$

$85(94 \%)$

$4(4 \%)$

$0(0 \%)$

$1(1 \%)$

$80(89 \%)$

$10(11 \%)$

$40(45 \%)$

$9(10 \%)$

$41(45 \%)$

$11(12 \%)$

$79(88 \%)$

$13(14 \%)$

$77(86 \%)$

$32(35 \%)$

$0(0 \%)$

$51(56 \%)$

$7(8 \%)$

Cycling competency

Don't know

Beginner

Intermediate

Expert

Cycle ownership/interest ${ }^{2}$

Own

Does not own - but interested in owning

Does not own - and uninterested in owning

Types of cycle journeys undertaken ${ }^{2}$

Campus (to/from)

Campus (within)

Shops

Work

Exercise

Recreation

Use of cycle helmet

Use helmet

Do not use helmet

$\begin{array}{rr}5 & (6 \%) \\ 3 & (3 \%) \\ 43(48 \%) \\ 39(43 \%)\end{array}$

$28(33 \%)^{2}$

$46(54 \%)^{2}$

$11(13 \%)^{2}$

$5(6 \%)^{2}$

$\mathrm{n} / \mathrm{a}$

$26(31 \%)^{2}$

$1(1 \%)^{2}$

$40(47 \%)^{2}$

$48(56 \%)^{2}$

$15(18 \%)^{2}$

$70(82 \%)^{2}$ $\mathrm{n} / \mathrm{a}$

$\mathrm{n} / \mathrm{a}$

$\mathrm{n} / \mathrm{a}$

$\mathrm{n} / \mathrm{a}$

$\mathrm{n} / \mathrm{a}$

$n / a$

$n / a$

$n / a$

$\mathrm{n} / \mathrm{a}$

$\mathrm{n} / \mathrm{a}$

$\mathrm{n} / \mathrm{a}$

n/a

$\mathrm{n} / \mathrm{a}$

$\mathrm{n} / \mathrm{a}$

$\mathrm{n} / \mathrm{a}$

$\mathrm{n} / \mathrm{a}$

$n / a$

$\mathrm{n} / \mathrm{a}$

$\mathrm{n} / \mathrm{a}$

$n / a$

$n / a$

$\mathrm{n} / \mathrm{a}$

$\mathrm{n} / \mathrm{a}$

$3(14 \%)^{1}$

$7(32 \%)^{1}$

$12(54 \%)^{1}$

$2(9 \%)^{3}$

$17(77 \%)^{3}$

$3(14 \%)^{3}$

$8(3 \%)$

16 (6\%)

$142(51 \%)$

115 (41\%)

$\mathrm{n} / \mathrm{a}$

$16(6 \%)^{1}$

$111(41 \%)^{1}$

$146(53 \%)^{1}$

$17(6 \%)^{2,4}$

$17(6 \%)^{3}$

$227(83 \%)^{2}$

$224(82 \%)^{3}$

$29(11 \%)^{2}$

$32(12 \%)^{3}$

$6(28 \%)^{1,3}$

$19(7 \%)^{2}$

$98(35 \%)^{1,3}$

$\begin{array}{lll}0 & (0 \%) \quad \mathrm{n} / \mathrm{a}\end{array}$

$37(14 \%)$

$0 \quad(0 \%)^{1,3} \quad 96(35 \%)^{2}$

$2(1 \%)^{1,3}$

$\begin{array}{lll}0 & (0 \%)^{1,3} \quad 7(3 \%)^{2}\end{array}$

$1(0 \%)^{1,3}$

$6(28 \%)^{1,3} \quad 116(42 \%)^{2}$

$109(40 \%)^{1,3}$

$17(75 \%)^{1,3} \quad 155(57 \%)^{2}$

$189(70 \%)^{1,3}$

$22(100 \%)^{1,3} \quad 80(29 \%)$

$272(100 \%)^{1,3}$

$0 \quad(0 \%)^{1,3} \quad 193(71 \%)$

$1(<1 \%)^{1,3}$ 
Experience of Johannesburg's cycle lanes

Use of Johannesburg cycle lanes

\begin{tabular}{lrrrrrr} 
Have used & $4(4 \%)$ & 21 & $(97 \%)^{1,3}$ & $35(13 \%)$ & $253(93 \%)^{1,3}$ \\
Have not used & $86(96 \%)$ & 1 & $(3 \%)^{1,3}$ & $238(87 \%)$ & $20(7 \%)^{1,3}$ \\
\hline
\end{tabular}

${ }^{1}$ Since these items related to activities integral to the intervention, it is likely that they will have changed simply as a result of the intervention itself.

${ }^{2}$ In the 'before-' and 'in the 'after-' questionnaire, these items were only answered by respondents who reported that they knew how to ride a bicycle; hence the smaller sample of responses to some of these items.

${ }^{4}$ This figure was corrected from $n=80(29.3 \%)$ who reported owning a bicycle in the 'before-' intervention questionnaire, but altered this response to "Does not own - but interested in owning" in the 'after-' intervention questionnaire. 
Table 3. Statistical analysis of changes in self-reported: cycling behaviour (types of journeys undertaken; use of safety helmet; and cycle lane use); cycling competency ('expert' vs. 'non-expert'); and interest in bicycle ownership before and after the intervention, amongst $n=281$ participants who responded to both the 'before-' and 'after-' questionnaire. Results are presented as the odds ratio (with associated $95 \%$ confidence intervals $[95 \% \mathrm{Cl}]$ in parentheses) of each criterion 'after-' vs. 'before-' the intervention.

Behaviour, competency

or interest (referent)

OR $(95 \% \mathrm{Cl})$

Explanation

Types of cycle journeys undertaken

'to the shops' (not)

$0.01(0.00,0.06)$

Much less likely to cycle to the shops

'to and from campus' (not)

$7.49(4.42,12.7)$

Much more likely to cycle to/from campus

'to work' (not)

$0.14(0.02,1.14)$

Less likely to cycle to work

'Recreation/enjoyment' (not)

$1.71(1.21,2.43)$

More likely to cycle for recreation

'Exercise' (not)

$0.90(0.64,1.27)$

No change in cycling for exercise

Use of cycle helmet

'wore helmet' (not) nntc ${ }^{1}$

All but one participant wore a helmet afterwards

Use of Johannesburg cycle lanes

'cycle on cycle lanes' (not)

$86.02(48.30,153.21)$

Much more likely to have cycled on cycle lanes

Cycling competency

'expert' (non-expert)

$1.58(1.13,2.21)$

More likely to consider oneself an expert cyclist

Interest in bicycle ownership 'interested in owning' (not)

$1.12(0.65,1.91)$

No change in bicycle ownership aspiration

${ }^{1}$ Because all but one participant reported that they wore helmets during/following the intervention (while $n=193$ did not wear a helmet before the intervention), it is not necessary to calculate (nntc) the $\mathrm{OR}(95 \% \mathrm{Cl})$ for this criterion. 
Table 4. Thematic analysis of free-text responses to each of the six open-ended items in the 'after-' intervention questionnaire (with exemplar quotes presented in inverted commas).

\section{1. 'Likes' of Johannesburg cycle lanes}

- Participants recognised the benefits of lanes reserved specifically, and exclusively, for use by cyclists:

"It's a personal space for bikes." - "They give you your own space."

"They are dedicated only for cyclers, which makes it easy for beginners."

- Dedicated space for cyclists was felt to make cycling safer, quicker, more enjoyable and more convenient:

"They are much safer. We not using same road as motorists."

"Fast to get home. Don't have to break for cars and traffic." - "Convenient."

"You don't have to worry about cars." - "You have the freedom to ride nicely."

- Aesthetic, lifestyle and financial benefits were somewhat secondary, but nonetheless evident:

"Cool." - "The design." - "Green." - "Environmentally friendly." - "They keep me fit." - "Free."

2. 'Dislikes' of Johannesburg cycle lanes

- Many participants felt there was nothing that they disliked about the lanes, and made a point of saying so:

"Nothing." - "Nothing really."

- Others were concerned that the lanes were narrow, and only wide enough for one cyclist at a time:

"They are too small. You can't overtake other riders."

- The lanes were felt to be too close to, and inadequately separated from, roads:

"The lane is too close to the cars."

"[The] yellow line [of raised studs is] not enough to keep cars away. Make a bigger buffer."

- Inadequate signage, particularly at intersections, made these confusing and hard to negotiate safely:

"When you come to the stop signs and robots it's challenging because there are no signs for bikers."

"The robots [traffic lights] do not make allowances for people [on bicycles] who are turning."

"Intersection is horrible. [I] almost died."

- The limited extent of the cycle lane scheme, and the they haphazardly began and ended:

"Only in certain areas." - "Not found everywhere."

"[The lanes] end in the middle of nowhere." - "Random stoppages of lanes."

- Poor surfacing of the lanes, rubbish/debris/holes (and parked cars), and the fact that they were not level:

"The bricks are slippery when going fast." - "The garbage on the lanes makes a distraction."

"The cars park on them. Some lanes are not level."

\section{Suggestions on improving Johannesburg cycle lanes}

- As with the number of participants with no dislike of the lanes, many offered no suggested improvements:

"No. They are perfect."

- Widen the lanes and separating them better from roads to prevent vehicles using/parking in these:

"Increase size [width] to accommodate two bicycles side-by-side."

"They should be wider to allow overtaking."

"Build a barrier to separate the lanes from cars."

"They should [have] a tiny pavement instead of yellow dividing thing [i.e. road studs]."

"Drivers need to respect those lanes." - "Cars park there... they cause obstructions."

- Using dedicated signs, traffic lights, separate lanes and personnel to help cyclists negotiate intersections:

"More highlighted" - "More visible, and road signs made more clearer. Alterations of signs."

"The [cycle] lanes should have their robots [traffic lights] as well."

"Adding traffic officers." - "Marshals to control."

"At the Stop streets the lanes are not visible, and the traffic circle [roundabout] is confusing."

- Complete/extend the lanes and ensure these are level, clean, shaded and unobstructed by rubbish:

"They should put in more [bicycle] lanes."

"They must make sure that they are level."

"Clean [broken] bottles on the lanes."

"Some streets don't have lanes, so it [the cycle lane scheme] is inconsistent."

\section{Experience of using the promotional/loan bicycle}

- Some participants found it fun, exhilarating, exciting and a challenging yet enjoyable new experience:

"It was really fun." - "Lovely." - "Awesome." - "It was amazing." - "Fun and refreshing." 
"It was kinda tough to ride at first, but as soon as the assistants helped me, I was able to get back at my feet and ride it." - "It was a good first time experience." - "Eye opener."

- But cycling was also difficult to master (particularly bicycles with a single gear and/or a back pedal brake):

"The brakes are confusing. I can't control them well."

- As a result, many participants found it tiring, and even (for some) painful, particularly on steep hilly roads:

"Exhausting on steep hill." - "Great, depending on one's fitness."

"It was a shock to my body, but ended up being fun."

- Likewise, a few less confident participants found it scary to cycle next/so close to busy roads:

"I almost died." - "Almost got injured." - "The motorists are a bit of a problem."

"Frightening around cars." - "It was good, but dangerous."

\section{Challenges experienced while using the promotional/loan bicycle}

- The principal challenge experienced related to cycling competency and related fitness issues:

"It was a learning curve... had to be very observant and to be careful in riding."

"I was looking to balance a lot, as I am a beginner." - "I couldn't cycle straight."

"I didn't have enough energy, and the peddling is challenging." - "Thigh pains. Unfit."

"Riding up [hill] was difficult." - "Steep hills." - "Physical challenges."

- There were also difficulties experienced as a result of cycling in a mixed-competency group:

"People were hitting the breaks continuously." - "Overcrowding in the lanes."

"Person in front was too slow."

- For some participants the bicycle they were loaned (and particularly its brakes) proved hard to use:

"Heavy single gear [on the loan bicycle used]." - "Steep hills on a one gear bike."

"When you are riding downhill on the lanes the brakes have to be suitable."

"The brakes on the bicycle weren't nice."

"The bicycle is too heavy." - "It goes too fast, the bicycle."

- Many of the issues raised previously regarding issues with the cycle lanes also featured here:

"Going back into lane after moving [out] for cars parked [in the cycle lane]."

"Cars parked in the lanes." - "The bicycle jumped over the yellow barriers."

"At intersections." - "When turning, the road does not allow a cyclist to turn in same way."

- Fear, and experiences, of accidents, though uncommon, clearly made an impression on some participants:

"People were falling. Made me scared." - "Accidents."

"Almost got hit by a car." - "I fell." - "I had a mini accident."

\section{Further comments regarding Johannesburg cycle lanes (open-ended)}

- By this stage in the intervention, many participants were tired and keen to complete the evaluation:

"Nothing. I'm tired."

- The final 'further comments' item also tended to elicit suggestions that had been raised previously:

"Widen." - "Level." - "Expand." - "Extend" - "Clean." - "Robots [for cycle lanes]."

- There were nonetheless those who felt that the cycle lanes (alone) were limited in scope and ambition:

"Put them [cycle lanes] at townships." - "The government should give everyone a bicycle." 
Figure 1. A selection of photographs captured by fieldworkers on their mobile phones during the implementation of the intervention in March/April 2016. From top to bottom: participants receiving competency and safety training; participants and instructors stretching during pre-ride warm-up sessions; participants taking part in the supervised cycle rides along the 'university corridor' cycle lanes; and students queuing up to participate in a subsequent cycle promotion event.

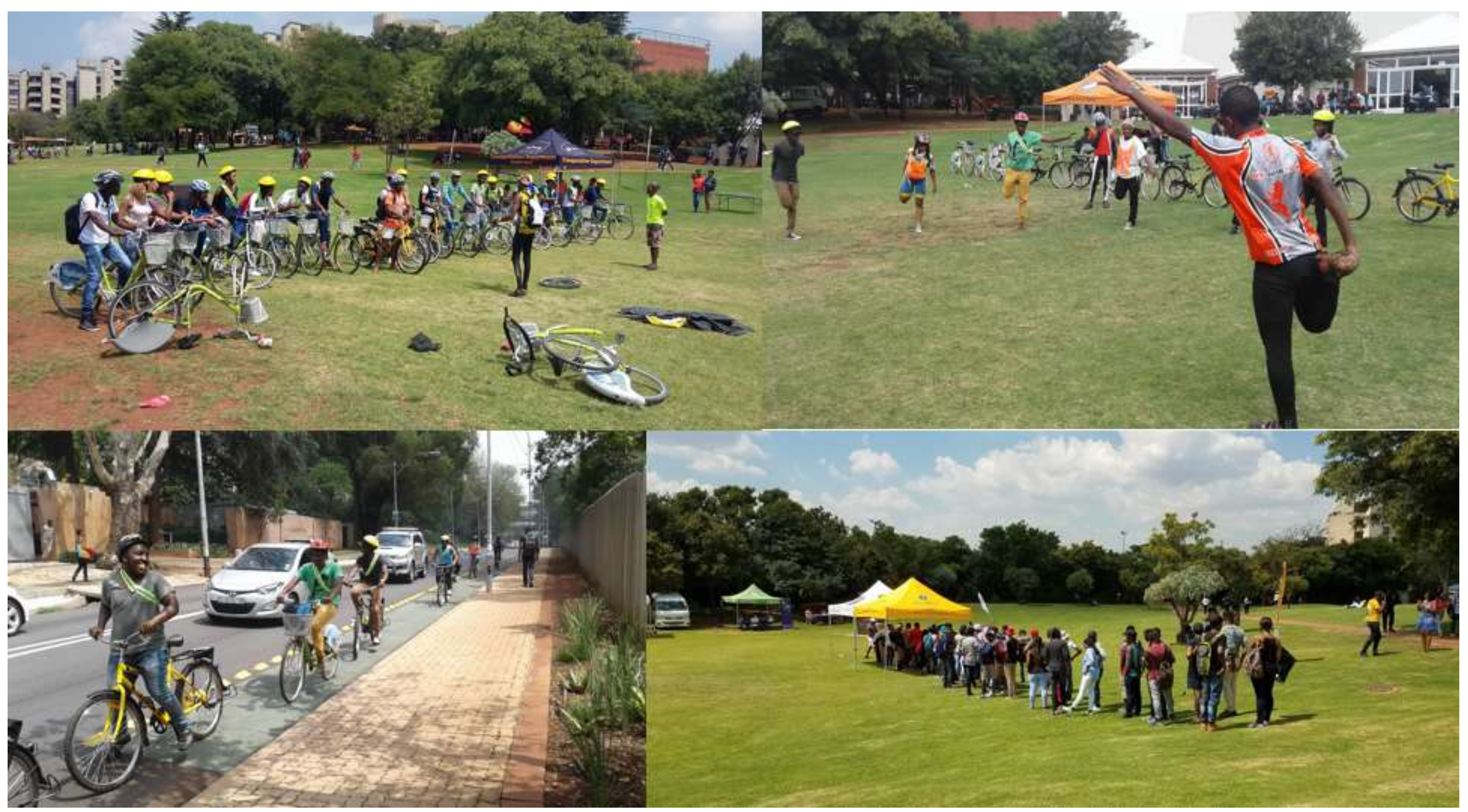

